\title{
SCOLIOSIS CAUSED BY SECTION OF DORSAL SPINAL NERVE ROOTS
}

\author{
J. R. PINCOTT, J. S. DAVIES, L. F. TAFFS
}

\begin{abstract}
From the Department of Histopathology, The Hospital for Sick Children, London, and the National Institute for Biological Standards and Control, London
\end{abstract}

\begin{abstract}
Experimental evidence has accumulated in recent years to suggest that scoliosis can be caused by asymmetrical spinal muscle weakness due to sensorineural loss, though this suggestion has not achieved universal acceptance. The evidence is supported by histopathological observations on cases of clinical idiopathic scoliosis. A study is presented in which cynomolgus monkeys had one, two or three dorsal spinal nerve roots cut. Scoliosis developed, convex to the damaged side; its severity was dependent on the number of nerve roots cut. Section of the first lumbar dorsal spinal nerve root had a marked tendency to cause scoliosis. The study supports the view that scoliosis may be caused by asymmetrical paraspinal muscle weakness acting through loss of proprioception.
\end{abstract}

The induction of scoliosis in experimental animals has been attempted by a variety of methods. Amongst these the sensory deprivation experiments of Liszka (1961) and of MacEwen (1973) were successful in causing scoliosis by section of the dorsal roots of spinal nerves. Doubt was cast on the validity of this method, however, when Alexander, Bunch and Ebbesson (1972) failed consistently to produce scoliosis, only 60 per cent of their animals developing a curve within 10 days of dorsal root section.

More recently, evidence has emerged (Taffs, Magrath and Lytton 1979; Pincott 1980; Pincott and Taffs 1982) which suggests that scoliosis can be caused by sensory deprivation at the spinal cord level in experimental animals. This is supported by further evidence from the field of clinical idiopathic scoliosis (Lloyd-Roberts et al. 1978; Pincott 1980) where damage of the dorsal root ganglia has been observed on post-mortem examination of the spinal cords of scoliotic patients. Both clinically and experimentally the sensory damage was on the convex side of the curve, suggesting that paraspinal muscular imbalance may be implicated in the causation of some cases of clinical idiopathic scoliosis. It has further been suggested that this mechanism may be mediated by muscular weakness due to proprioceptive loss on the convex side of the curve.

J. R. Pincott, MB BS, MRCPath, Senior Lecturer

Department of Histopathology, Hospital for Sick Children, Great Ormond Street, London WCIN 3JH, England.

J. S. Davies, MA, MB, FRCS, Consultant Orthopaedic Surgeon

Worcester Royal Infirmary, Worcester WR1 3AS, England.

L. F. Taffs, PhD, FRCVS, Scientist and Veterinary Adviser

The National Institute for Biological Standards and Control, Holly

Hill, Hampstead, London NE3 6RB, England.

Requests for reprints should be sent to Dr J. R. Pincott.

(C) 1984 British Editorial Society of Bone and Joint Surgery $0301-620 \mathrm{X} / 84 / 1025 \$ 2.00$
The present study was designed to clarify the question of whether sensory deprivation at the level of the spinal nerve could cause scoliosis and whether the resultant curve would be convex to the damaged side. Cynomolgus monkeys were chosen for this study, partly because of their phylogenetic similarity to man, and partly to provide continuity with previous work (Taffs $e t$ al. 1979; Pincott 1980; Pincott and Taffs 1982). The continuity of experimental detail was preserved as far as possible in all aspects of the study, but particularly in the method and period of observation of the animals and the grading of the resultant curves, so as to provide comparability with these earlier studies. Localised sensory deprivation was achieved by section of dorsal roots of spinal nerves.

\section{MATERIALS AND METHODS}

Adolescent cynomolgus monkeys (Macaca fascicularis) were used in the study; these monkeys reach maturity at three to four years of age. Twenty-three animals were anaesthetised with ketamine hydrochloride and pentobarbitone sodium, and spinal laminectomies were performed. Six control animals received laminectomies alone while of the remaining 17 animals, 10 had a single intradural dorsal rhizotomy, five had two successive roots sectioned, and in two animals three successive roots were cut. Of these animals, a single ventral rhizotomy was also performed in three instances, once in association with no dorsal rhizotomies, once with two successive dorsal rhizotomies, and once with three successive dorsal rhizotomies.

All animals were assessed clinically for evidence of scoliosis over a period of one to three weeks. This period of observation was selected to provide continuity with previous work on these animals (Pincott and Taffs 1982), the observation time being kept to a minimum for ethical 
reasons. Although the animals were also observed for evidence of illness which might lead to distress and consequent termination of that particular experiment, no such problem was encountered and all animals ran to the full period of assessment.

At the end of the period of clinical observation, the animals were sedated with ketamine hydrochloride and pentobarbitone sodium, assessed visually for evidence of scoliosis, and if scoliosis was seen or suspected confirmatory radiography was performed on which the severity of the curve was graded as mild, moderate or severe, as classified in the previous study (Pincott and Taffs 1982). The animals were then killed and fixed by perfusion with acetic formol saline. A detailed dissection of the spines was carried out to confirm the number and level of spinal nerve roots cut, and to detect any additional damage.

The results were tabulated and the presence or absence of scoliosis compared with the number, level and side of sectioned spinal nerve roots in each animal.

\section{RESULTS}

The number, levels and side of spinal nerves cut is compared with the side and severity of the resulting scoliosis in Table I.

Side of curve. In every instance where scoliosis developed the convexity of the curve was to the side on which the rhizotomies had been performed, whether this was left or right. The apex of the curve was always at the level of the rhizotomies.

Number of rhizotomies needed to produce curve. Six animals had laminectomies performed with no dorsal rhizotomy, and in one of these animals a single ventral nerve root was cut; none of the six animals developed scoliosis.

Ten animals had a single dorsal nerve root cut, with no ventral rhizotomies; three of these animals developed a scoliosis, one severe and two mild. All three had had the dorsal root of $\mathrm{Ll}$ sectioned, and of the remaining seven animals in this group, only one had received a dorsal rhizotomy at $\mathrm{Ll}$.

Five animals had had two successive dorsal roots cut, one of which had also had a single ventral rhizotomy. Three of these developed a scoliosis, two severe and one mild, and in each the dorsal root of $\mathrm{L} 1$ had been sectioned. In the two animals which did not develop a curve, the dorsal root of $\mathrm{Ll}$ had not been cut; the animal with the additional ventral rhizotomy was one of those which failed to develop a curve.

Two animals had three successive dorsal rhizotomies, one with an additional single ventral rhizotomy. Both animals developed a moderate scoliosis, and in both the dorsal root of $\mathrm{Ll}$ was amongst the roots sectioned.

Severity of curve. The severity of the curve did not correlate with either the number of dorsal roots cut, or the spinal level of these roots.

Ventral root section. There was poor correlation with the development of scoliosis in the three cases where a single ventral nerve root was cut. In only one of these did a curve develop, and this was in association with section of three successive dorsal roots. In the other two cases, where a curve did not develop, one had a ventral root cut in association with two dorsal roots, and one had a ventral rhizotomy alone.

Time taken to develop curve. Animals $Q, V$, and $\mathrm{X}$ developed a visible curve on the day of operation and the curve in each animal was maintained until the end of the period of observation and confirmed radiologically. Animal $\mathrm{W}$ developed a curve on the second day, animal $M$ on the fourth day, animal $L$ on the sixth and animal $N$ on the eighth day. In animal $J$ the curve was only detected on sedation and examination before radiography and death on the twentieth day.

Table I. Spinal nerve roots sectioned in each animal and incidence of scoliosis

\begin{tabular}{|c|c|c|c|}
\hline Animal & $\begin{array}{l}\text { Level of } \\
\text { rhizotomy }\end{array}$ & $\begin{array}{l}\text { Side of } \\
\text { rhizotomy }\end{array}$ & $\begin{array}{l}\text { Side of convexity } \\
\text { and severity of } \\
\text { curve }\end{array}$ \\
\hline A & Nil & NA & NA \\
\hline B & Nil & NA & NA \\
\hline $\mathrm{C}$ & Nil & NA & NA \\
\hline D & $\mathrm{L} 2$ & Left & NA \\
\hline E & $\mathrm{L} 2$ & Left & NA \\
\hline $\mathbf{F}$ & L4 & Left & NA \\
\hline G & Nil & NA & NA \\
\hline $\mathrm{H}$ & $\begin{array}{l}\mathrm{L2}, \mathrm{L} 3 \\
\text { ( + ventral L3) }\end{array}$ & Left & NA \\
\hline J & $\mathrm{T} 12, \mathrm{Ll}$ & Left & Left, mild \\
\hline K & L2 & Left & NA \\
\hline L & $\mathrm{T} 12, \mathrm{Ll}$ & Left & Left, severe \\
\hline $\mathbf{M}$ & $\begin{array}{l}\mathrm{L1}, \mathrm{L} 2, \mathrm{L3} \\
\text { ( + ventral L1) }\end{array}$ & Left & Left, moderate \\
\hline$N$ & $\mathrm{Ll}$ & Right & Right, severe \\
\hline O & $\begin{array}{l}\text { Nil } \\
(+ \text { ventral T12) }\end{array}$ & Right & NA \\
\hline $\mathbf{P}$ & L3 & Right & NA \\
\hline Q & $\mathrm{L} 1, \mathrm{~L} 2$ & Right & Right, severe \\
\hline $\mathbf{R}$ & $\mathrm{Nil}$ & NA & NA \\
\hline $\mathbf{S}$ & L2, L3 & Right & NA \\
\hline $\mathrm{T}$ & L2 & Right & NA \\
\hline $\mathrm{U}$ & $\mathrm{Ll}$ & Left & NA \\
\hline$v$ & $\mathrm{Ll}$ & Left & Left, mild \\
\hline W & $\mathrm{Ll}$ & Left & Left, mild \\
\hline $\mathrm{X}$ & L1, L2, L3 & Right & Right, moderate \\
\hline
\end{tabular}

$\mathrm{NA}=$ Not applicable, i.e. no curve developed 


\section{DISCUSSION}

The development of scoliosis, which was always convex to the side of the sectioned dorsal spinal nerve roots, was interpreted as supporting the view (Pincott 1980; Pincott and Taffs 1982) that scoliosis can result from spinal muscular imbalance caused by unilateral sensory, probably proprioceptive deprivation and consequent weakness.

The proportion of animals which developed a scoliosis increased with the number of dorsal nerve roots cut. Only three of 10 animals with a single rhizotomy developed a curve, while three of five animals with two successive dorsal roots cut, and both animals with three successive dorsal roots cut became scoliotic. This was taken to imply that after the loss of a single segment of sensory innervation, neural or muscular compensation by adjacent spinal segments could take place. When the sensory deprivation was more extensive, however, the capacity for compensation was correspondingly reduced, and a scoliosis developed.

The section of a single ventral spinal nerve root appeared to have no influence on the development of scoliosis. The observation is rendered less valid, however, as the procedure was only carried out in three animals, this aspect not being a primary objective of the investigation.

It was noted with interest that in each of the eight animals where scoliosis had developed, the dorsal root at L1 had been one of those sectioned-indeed in three instances it had been the only root sectioned. On the other hand, of the other 10 animals where a dorsal root or roots had been cut without causing scoliosis, only one had $\mathrm{Ll}$ sectioned. This observation had no obvious single explanation. The spinal nerves at $\mathrm{Ll}$ in the cynomolgus monkeys do not appear to be larger than those at other levels. No major arterial blood supply was seen to accompany the dorsal spinal root at this level, and no infarction of the cord was seen on post-mortem examination, though a small amount of local meningeal haemorrhage was seen in some scoliotic and some nonscoliotic animals. Despite this, a loss of vascular supply would seem to provide the most likely explanation of this observation (Dommisse 1980).

The appearance of a scoliotic curve in three animals on the day of operation was considered not to be the result of surgical trauma as a similar amount of tissue damage was seen on post-mortem dissection in the six control animals. These had received laminectomies without rhizotomy and none had developed scoliosis.

The present study confirms the observations of Liszka (1961) and MacEwen (1973) that dorsal root section can cause scoliosis. It demonstrates in addition that the proportion of cases in which scoliosis develops is dependent on the number of dorsal roots cut. This fact may explain the apparent difference between our results and those of Alexander et al. (1972) who produced a scoliosis in 60 per cent of animals by dorsal rhizotomy alone but did not specify how many animals developed scoliosis for each number of roots cut.

The study also confirms our previous observations (Pincott and Taffs 1982) that loss of afferent impulses due to damage within the spinal cord can cause scoliosis with its convexity to the side of the damage. In our previous study, a minimum number of one and a half spinal segments had had to be damaged for scoliosis to develop, whereas in the present study scoliosis developed in 30 per cent of animals with one root cut, and 60 per cent with two roots cut, thus agreeing well with the previous study.

It is concluded that unilateral loss of afferent neural impulses at spinal nerve level can cause scoliosis by means of spinal muscular imbalance, and that the probable mechanism of this imbalance is through unilateral weakness due to proprioceptive loss as discussed in a previous paper (Pincott and Taffs 1982). These conclusions are consistent with previous experimental work, and with histopathological observations on clinical cases of scoliosis in humans (Lloyd-Roberts et al. 1978; Pincott 1980).

The authors are grateful for the financial support of the Laming Evans Research Fund of the Royal College of Surgeons of England. Excellent technical assistance was provided by Miss Glynis Dunn and the manuscript was typed by Miss Julie Smith.

\section{REFERENCES}

Alexander MA, Bunch WH, Ebbesson SOE. Can experimental dorsal rhizotomy produce scoliosis? J Bone Joint Surg [Am] 1972:54-A : 1509-13. Dommisse GF. The arteries, arterioles and capillaries of the spinal cord: surgical guidelines in the prevention of postoperative paraplegia. Ann $R$ Coll Surg Engl 1980;62:369-76.

Liszka O. Spinal cord mechanisms leading to scoliosis in animal experiments. Acta Med Pol 1961:2:45-63.

Lloyd-Roberts GC, Pincott JR, McMeniman P, Bayley IJL, Kendall B. Progression in idiopathic scoliosis: a preliminary report of a possible mechanism. J Bone Joint Surg [Br] 1978;60-B:451-60.

MacEwen GD. Experimental scoliosis. Clin Orthop 1973;93:69-74.

Pincott JR. Observations on the afferent nervous system in idiopathic scoliosis. In: Zorab PA, Siegler D, eds. Scoliosis (1979). London and New York: Academic Press, 1980:45-59.

Pincott JR, Tafis LF. Experimental scoliosis in primates: a neurological cause. J Bone Joint Surg [Br] 1982;64-B :503-7.

Taffs LF, Magrath DI, Lytton NA. Monkey scoliosis. Lancet 1979;i: 1078-9. 